\title{
Mechanical and optical properties of surface micromachined torsional mirrors in silicon, polysilicon and aluminum
}

\author{
V.P. Jaecklin, C. Linder, J. Brugger and N.F. de Rooij \\ Institute of Microtechnology (IMT), University of Neuchâtel, Rue A.-L. Bneguet 2, CH-2000 Neuchatel (Swizzerland)
}

J.-M. Moret and R. Vuilleumier

Swiss Center for Electronics and Microtechnology Inc. (CSEM), Maladière 71, CH-2000 Neuchâtel (Switzerland)

\begin{abstract}
This paper presents a comparative study of surface micromachined structures fabricated in three different materials, using torsional micromirrors as test vehicle. The devices are realized in single-crystal silicon, polycrystalline silicon and aluminum. Mechanical properties such as internal strains, sticking phenomena, yield strains and endurance test resistance as well as optical properties such as surface refiectivities and scattering characteristics are investigated on the devices. the characterization points out that the silicon and polysilicon structures present higher yield strains and are less prone to surface sticking while the aluminum mirrors have higher surface reflectivities.
\end{abstract}

\section{Introduction}

Torsional micromirrors are gaining interest for dense light modulator arrays which can be used in laser printing, projection display or optical interconnection devices. So far, the fabrication of aluminum torsional mirrors [1-3], silicon torsional mirrors $[4,5]$ and polysilicon torsional mirrors [6] has been reported. We have realized torsional micromirrors in these materials using the same set of masks; this approach allows the three technologies to be compared.

This paper reports the fabrication methods for the three different materials. The electro-mechanical switching of the micromirrors is discussed. Further, results concerned with mechanical and optical properties of the devices are presented. Internal strains, sticking phenomena, maximum tensile strains, surface reflectivities and scattering characteristics are investigated on simple test structures, while the resistance to endurance testing has been observed on a polysilicon torsional mirror. Finally, as promising application, a two-dimensional polysilicon mirror array is presented.

\section{Fabrication}

The single crystal silicon devices are fabricated using a combination of silicon fusion bonding (SFB), wafer thinning in potassium hydroxide $(\mathrm{KOH})$, and patterning by dry etching (see Figs. 1(a) and 2) [7]. The process starts with two phosphorus-doped $(0.03 \Omega \mathrm{cm})$, double- side polished, $280 \mu \mathrm{m}$ thick silicon wafers with (100) crystalline orientation which are thermally oxidized to $1.5 \mu \mathrm{m}$. After a cleaning and hydrophilization procedure in $\mathrm{HNO}_{3}$ and $\mathrm{H}_{2} \mathrm{SO}_{4}: \mathrm{H}_{2} \mathrm{O}_{2}$, both wafers are aligned and 'sandwiched' face to face [8]. The hydrobond forces are strong enough to keep the wafers together on the $\mathrm{SiO}_{2}-\mathrm{SiO}_{2}$ contact surfaces while transporting the stack into the high temperature furnace. SFB at $1100^{\circ} \mathrm{C}$ for about $4 \mathrm{~h}$ seals the wafers together [9]. Then, the thermal oxide on the upper wafer is removed, and the wafer is thinned down to a thickness of about $2 \mu \mathrm{m}$ in a $40 \% \mathrm{KOH}$ solution at $60^{\circ} \mathrm{C}$. The thickness of the membrane is defined by a timed stop. A further delicate processing step is the etching of the submicrometer wide suspension beams, which guarantee the high flexibility and consequently the pivoting of the mirrors at low voltages. A standard photoresist is used for the patterning of the silicon by dry etching in a $\mathrm{C}_{2} \mathrm{ClF}_{5} /$ $\mathrm{SF}_{6}$ plasma [10]; high selectivity, controlled undercut, and almost vertical sidewalls are accomplished. The final processing step is the release of the mechanically movable parts (Fig. 2(d)); the wafers are immersed in BHF.

An overview of the polysilicon fabrication sequence is given in Fig. 3; for a detailed description, we refer to an earlier publication [11]. A 5 wt.\% phosphorusdoped CVD silicon dioxide (low temperature oxide) with a thickness of $2 \mu \mathrm{m}$ serves as sacrificial layer (Fig. 3(a)). A second, $2 \mu \mathrm{m}$ thick polysilicon is deposited by LPCVD (thermal decomposition of silane) at 600 


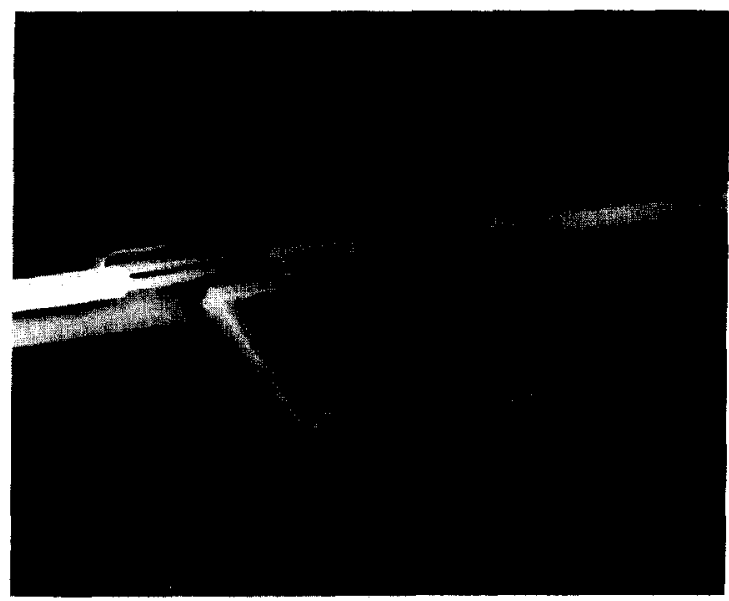

(a)

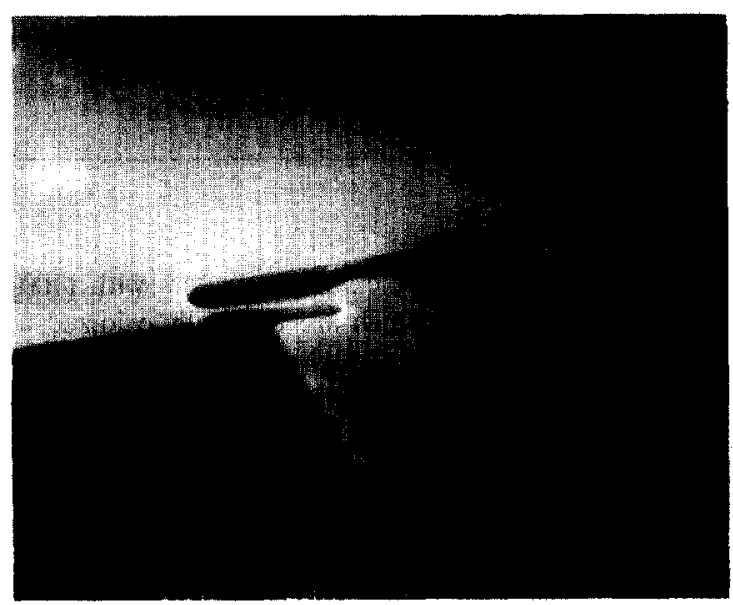

(b)

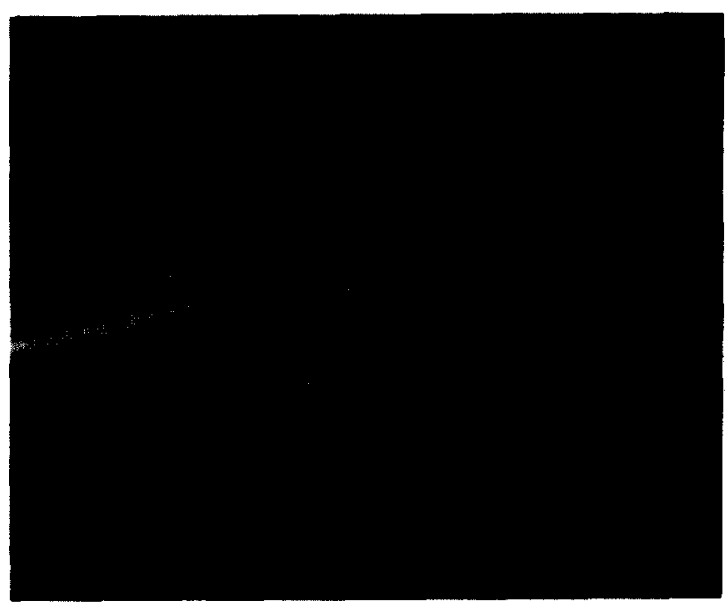

(c)

Fig. 1. SEM top views showing torsional micromirrors fabricatec in: (a) single crystal silicon, (b) polycrystalline silicon, (c) aluminum.
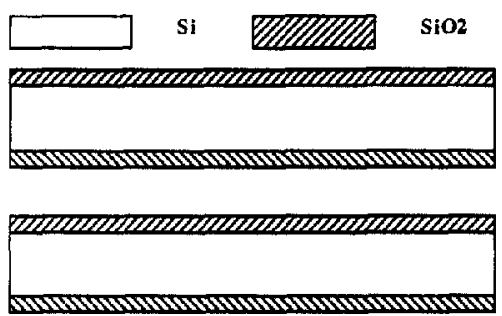

(a)

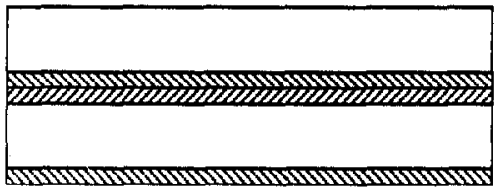

(b)

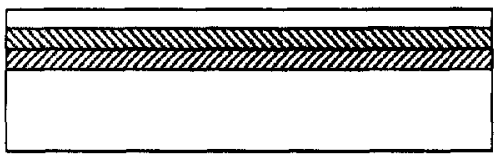

(c)

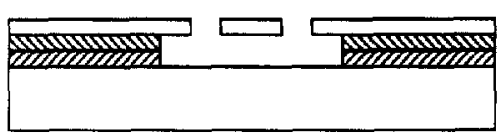

(d)

Fig. 2. Single mask silicon process: (a) hydrophilization of two thermally oxidized $(1.5 \mu \mathrm{m} \mathrm{SiO}$ ) silicon wafers, (b) prebonding due to physical contact and SFB in fumace, (c) thinning of upper wafer in $\mathrm{KOH}$, (d) patterning of silicon membrane and liberating of device by timed BHF etching.

${ }^{\circ} \mathrm{C}$ and $200 \mathrm{mTorr}$. Thermal annealing in nitrogen reduces the as-deposited, built-in compressive strain; for our polysilicon, the optimum condition is an anneal at $1050{ }^{\circ} \mathrm{C}$ for $30 \mathrm{~min}$. During the anneal, it is also doped by diffusion from the sacrificial layer as well as from a second phosphorus-doped oxide on top of it (Fig. 3(b)). Afterwards follows the same processing sequence that has been described for the single crystal silicon devices.

The fabrication of the aluminum devices employs a similar sequence to that for the polysilicon structures; thus, for this description Fig. 3 can also be used. A $2 \mu \mathrm{m}$ thick aluminum (Al1\% $\mathrm{Si}$ - alloy of pure aluminum and $1 \mathrm{wt} . \%$ of silicon) film is sputter deposited over the P-doped $\mathrm{CVD} \mathrm{SiO}_{2}$. In order to release the initial compressive stress, an annealing in $\mathrm{N}_{2}$ atmosphere at $450{ }^{\circ} \mathrm{C}$ for $30 \mathrm{~min}$ is performed. Afterwards, the film is structured by dry etching employing a $\mathrm{Cl}_{2}-\mathrm{SiCl}_{4}-\mathrm{N}_{2}$ chemistry. The final, delicate process step is the releasing of the aluminum structures. Since BHF etching will also attack the aluminum, the selectivity of $\mathrm{SiO}_{2}$ to $\mathrm{Al}$ has to be increased. The etch rate of aluminum can 
Si

P-doped

CVD SIO2

Polysilicon/

Aluminum
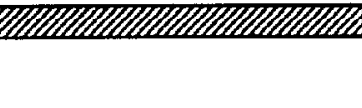

(a)

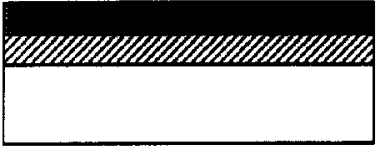

(b)

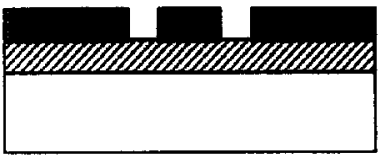

(c)

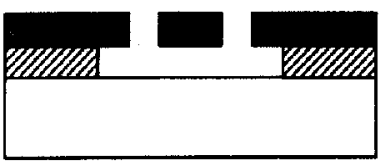

(d)

Fig. 3. Single mask polysilicon/aluminum process: (a) deposition of $2 \mu \mathrm{m}$ P-doped CVD $\mathrm{SiO}_{2}$, (b) deposition of $2 \mu \mathrm{m}$ of polysilicon/ aluminum, (c) patterning by dry etching, (d) liberating structures.

TABLE 1. Summary of properties of the three materials

\begin{tabular}{llll}
\hline Property & Mono-Si & Poly-Si & Al \\
\hline Max. temperature $\left({ }^{\circ} \mathrm{C}\right)$ & 1100 & 1050 & 450 \\
Time (h) & 4 & 0.67 & 0.5 \\
Switching voltage (V) & 43 & 15 & 7 \\
Max. freestanding & 200 & 400 & 100 \\
beam length $(\mu \mathrm{m})$ & & & \\
Yield strain (\%) & 1.7 & 2.3 & 0.6 \\
Surface reflectivity (\%) & 38.1 & 31.4 & 66.5 \\
\end{tabular}

be suppressed by chemically biasing the reaction towards electrochemical passivity with small amounts of strong oxidizers [12]. Added potassium dichromate $\left(\mathrm{K}_{2} \mathrm{Cr}_{2} \mathrm{O}_{7}\right)$ is very efficient [13]. The following process has given optimum results: before etching, the chips are immersed in a $0.01 \mathrm{M}$ water solution of $\mathrm{K}_{2} \mathrm{Cr}_{2} \mathrm{O}_{7}$ for $30 \mathrm{~min}$ at $20{ }^{\circ} \mathrm{C}$, this step produces a thin layer of protective $\mathrm{Al}_{2} \mathrm{O}_{3}$. Then, the chips are etched in a $0.005 \mathrm{M}$ solution of $\mathrm{K}_{2} \mathrm{Cr}_{2} \mathrm{O}_{7}$ in BHF (7:1) at a temperature of $0^{\circ} \mathrm{C}$ for about $2.5 \mathrm{~h}$. The selectivity of etch velocities is more than $\mathbf{5 0}$ for etching P-doped CVD $\mathrm{SiO}_{2}$ and aluminum, respectively. As can be seen in Fig. 1(c), the surface of the etched aluminum gets very rough.
The maximum temperature a technology requires for realizing mechanical devices is a critical parameter if the processing follows the fabrication of the IC components. Table 1 indicates the maximum temperatures for the three investigated technologies; while the fabrication of the silicon and polysilicon devices require temperatures above $1000^{\circ} \mathrm{C}$, the maximum temperature for the aluminum structures is limited to $450{ }^{\circ} \mathrm{C}$.

\section{Mechanical characterization}

The torsional micromirrors used for characterization are shown in Fig. 1. They are $30 \times 30 \mu \mathrm{m}$ squares suspended by $15 \mu \mathrm{m}$ long and about $0.6 \mu \mathrm{m}$ wide beams. Their rest and tilted $\left(3.8^{\circ}\right)$ positions are visualized in Fig. 4, and their switching voltage $V_{1}$ are summarized in Table 1 . Since under-etching depends on the material, it produces unequal submicrometer beam widths (see Fig. 1(a) and (b)). This mainly explains the voltage difference between the silicon (43 V) and polysilicon devices $(15 \mathrm{~V})$, that between polysilicon and aluminum devices $(7 \mathrm{~V})$ being essentially due to a difference in the Young's moduli.

By observing the buckling of doubly clamped beams (compressive stress) and using the Euler's criterion for calculation, the internal strain can be determined [14]. Except for the unannealed aluminum structures, all the $200 \mu \mathrm{m}$ long bridges (polysilicon $400 \mu \mathrm{m}$ ) have not shown any buckling. Hence, the computed internal compressive strain is below $329 \mathrm{ppm}$ ( $400 \mu \mathrm{m}$ bridge, below $82 \mathrm{ppm}$ ).

Sticking is also examined on the bridge structures. The maximum lengths, the beams can stand free in more than $80 \%$ of the observations, are reported in Table 1; this is the status after the final rinse in alcohol. Comparatively long polycrystalline silicon bridges ( 400 $\mu \mathrm{m})$ are completely free standing after processing. This may be due to the increased surface roughness of the polysilicon [15].

Yield strains are established by determining the maximum lateral bending of cantilevers (Fig. 5) before they break (silicon, polysilicon) or before they deform plastically (aluminum). The maximum tensile strains are calculated by the non-linear beam theory [16]. The calculation starts with the classic bending equation [17]

$\frac{1}{r(x, y)}=\frac{M(x, y)}{E I}$

where $r(x, y)$ is the curvature radius, $M(x, y)$ is the bending moment, $E$ is Young's modulus, and $I$ is the moment of inertia. In the case of a rectangular cross section, the moment of inertia is $I=1 / 12\left(w^{3} t\right)$, where $w$ is the beam width and $t$ is the beam thickness. The curvature radius $r$ can be rewritten as differential. If $L$ is the 

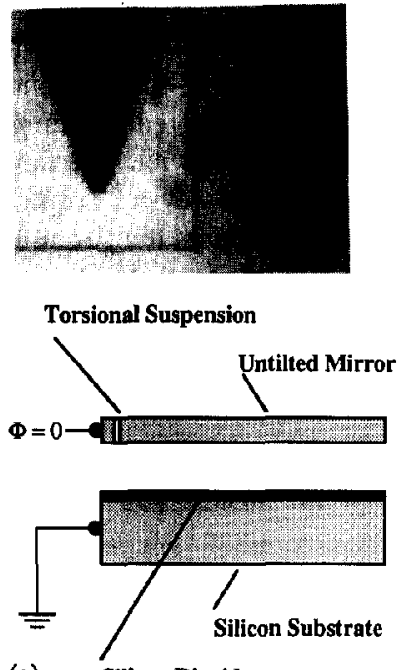

(a) Silicon Dioxide
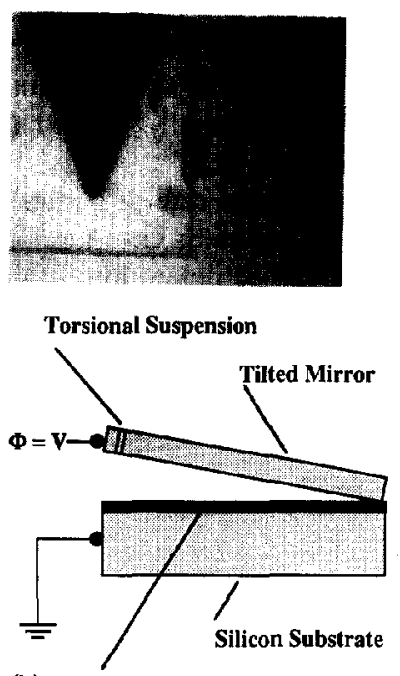

(b) Silicon Dioxide

Fig. 4. Optical micrographs and schematic drawings showing top and side views, respectively, of a silicon mirror: (a) rest position $\left(0^{\circ}\right)$, (b) tilted position $\left(3.8^{\circ}\right)$

length of the cantilever and $l$ is the projection length of the beam at maximum bending on the undeflected cantilever, the following intermediate solution for the differential equation is obtained

$l=L\left(\frac{2 E(p)}{K(p)}-1\right)$

The quantities $K(p)$ and $E(p)$ are complete elliptic integrals of the first and second kind, respectively. By numerical methods the variable $p$ can be determined. The maximum strain (which occurs at the clamped end) is [16]

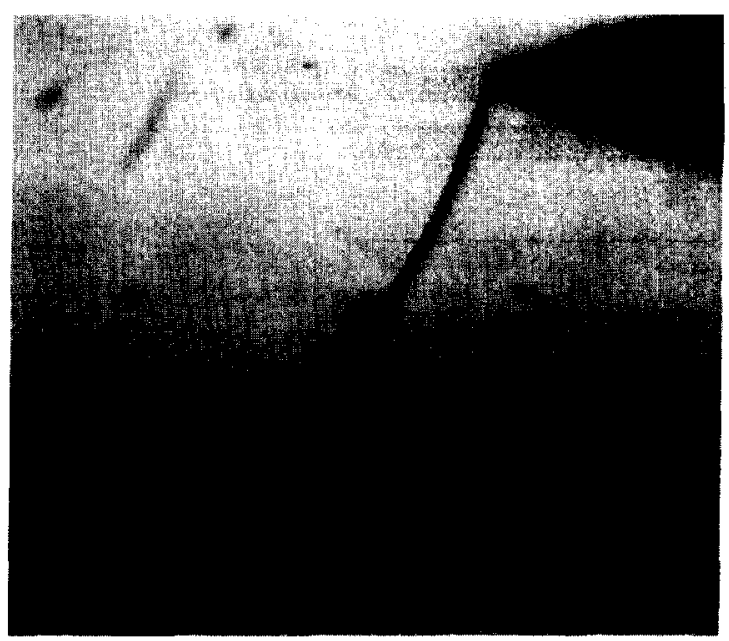

(a)

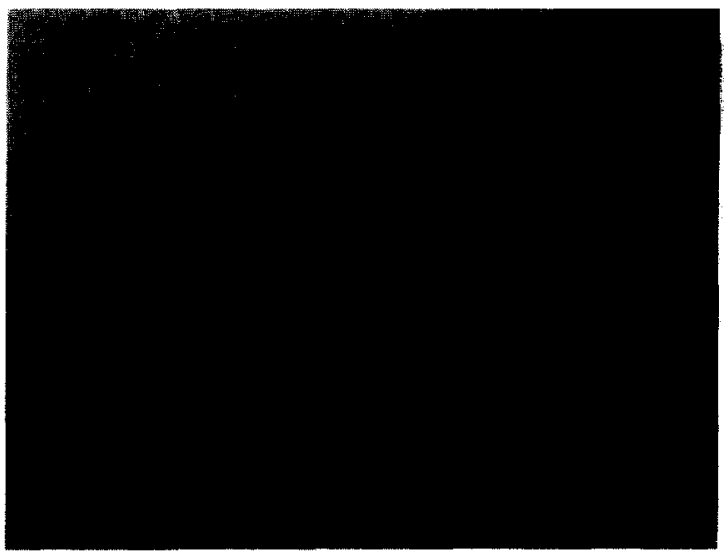

(b)

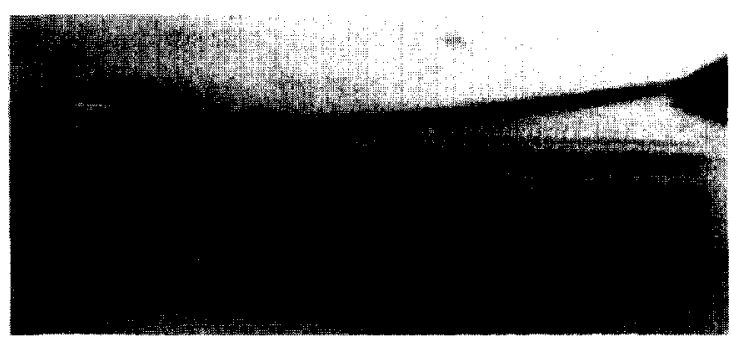

(c)

Fig. 5. Optical micrographs showing maximum lateral bending of cantilevers with identical dimensions before yielding: (a) single crystal silicon (fracture), (h) polycrystalline silicon (fracture), (c) aluminum (plastic deformation).

$$
\begin{aligned}
\epsilon_{ \pm \max } & = \pm \frac{M(0,0) w}{2 E I}-\frac{F}{w t E} \\
& = \pm p K(p) \frac{w}{L}-\frac{1}{12} K^{2}(p)\left(\frac{w}{L}\right)^{2}
\end{aligned}
$$


Hence, based on the maximum lateral bending as shown in Fig. 5 and the geometric dimensions (200 $\mu \mathrm{m}$ long, $3.8 \mu \mathrm{m}$ wide and $2 \mu \mathrm{m}$ high cantilevers), the strain limits can be calculated using eqn. (3). As can be seen in Table 1 for silicon beams in the $\langle 110\rangle$ direction, an average fracture strain of $1.6 \pm 0.1 \%$ has been found; the uncertainty is given by the difficulty of measuring precisely the width of the beams. This strain limit can be compared to measurements done on silicon whiskers by Eisner reporting a value of $2.03 \%$ [18], Pearson et al. reporting a maximum fracture strain of $2.6 \%$ [19], and Johansson et al. reporting an average fracture strain for $\langle 110\rangle$ silicon cantilevers of $2.0 \%$ [20]. On polysilicon structures, a fracture strain of $2.1 \pm 0.1 \%$ has been measured, which is higher than the limit of $1.72 \%$ reported by Tai and Muller [16]. The yield strain for aluminum (Al1\%Si) cantilevers has been observed to be $0.5 \pm 0.03 \%$; this is higher than the value $(0.3 \%)$ established for aluminum (Al5\%Si) in traditional macromechanical yield strain tests [21]. In our tests, the stress concentration at the clamped edge has been ignored; therefore, the actual strain limits may be even higher. A major advantage of this method, however, is that only geometric values and no material properties are required for determining the yield strain. Furthermore, fracture strength of brittle materials should be determined by statistical methods [22]. The reported results are based on an average value of five measurements; hence, the statistical significance is limited.

Fatigue effects are another domain of interest. So far, we have only performed endurance testing on polysilicon structures. During $120 \mathrm{~h}$ a micromirror was continuously cycled at frequencies of 1 and $10 \mathrm{kHz}$ so that a total of $10^{9}$ cycles was performed. At regular intervals the switching characteristics were investigated. The basic switching characteristic is as follows. When a voltage higher than $V_{1}$ (switch voltage) is applied on

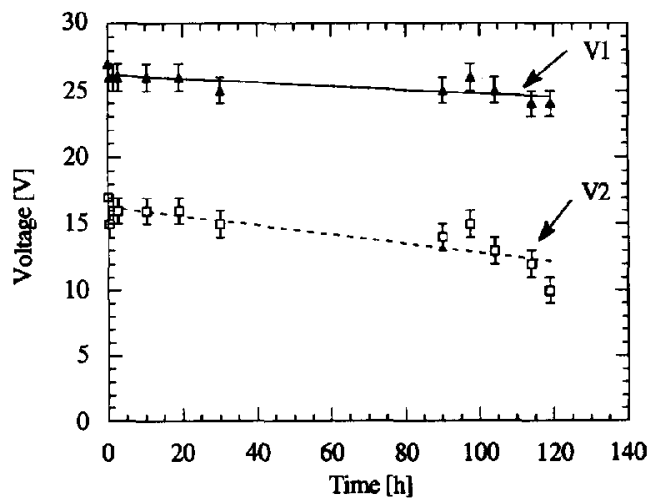

Fig. 6. Drift of switching voltage $V_{1}$ and release voltage $V_{2}$ during endurance test for a polysilicon torsional mirror (a total of $10^{9}$ cycles were performed). the address electrode, the electrically grounded mirror rotates by an angle of $3.8^{\circ}$ and hits the landing electrode [6]; the latter is also electrically grounded to prevent charge sticking effects. To release the mirror from the landing electrode, the address voltage is reduced below $V_{2}$ (release voltage). A significant drift of the switch and the release voltage has been observed during the test (Fig. 6). For example the release voltage $V_{2}$ was initially $17 \mathrm{~V}$; at the end of the test, it was $10 \mathrm{~V}$. We believe that these changes are due to trapped charges in the dielectric layer. A measurement which seems to confirm this hypothesis is that $V_{1}$ and $V_{2}$ slowly increased after the test was finished. The fact that the resonance frequency did not shift during the whole test is of more importance.

\section{Optical characterization}

The optical properties of the mirror surfaces are of great importance in view of future applications. Figure 7 shows the scattering of a laser beam $(633 \mathrm{~nm})$ as a function of the incident angle (measurements are performed on an ellipsometer). No scattering is observed for narrow angles - the intensity follows the Gaussian distribution of the incident laser beam (Fig. 7(a)). However, at wider angles there is some scattering
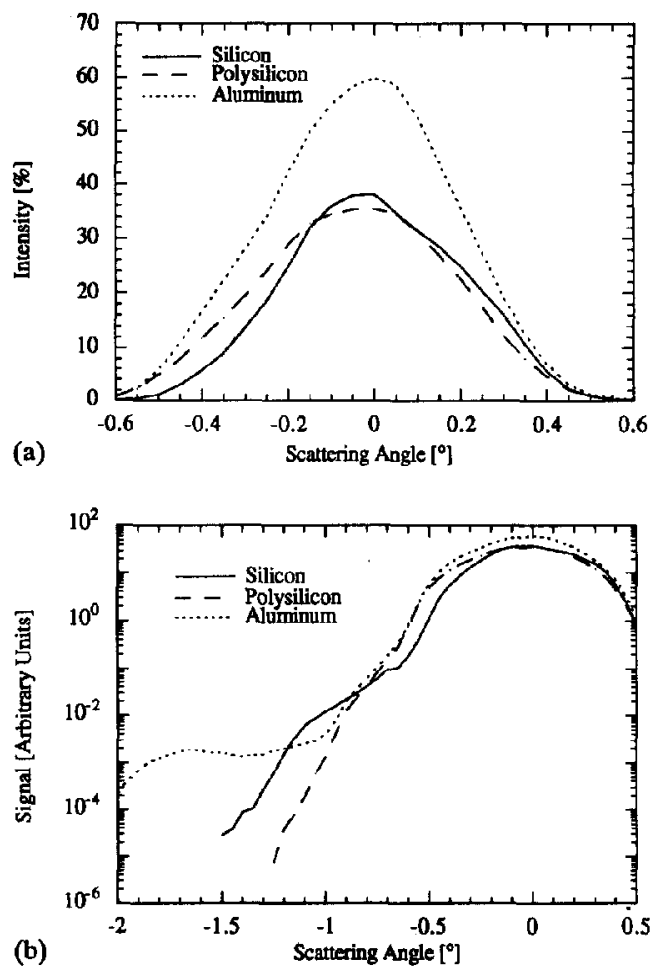

Fig. 7. Forward scattering of silicon, polysilicon and aluminum mirrors: (a) narrow angle scattering at a linear scale, (b) wide angle scattering at a logarithmic scale. 


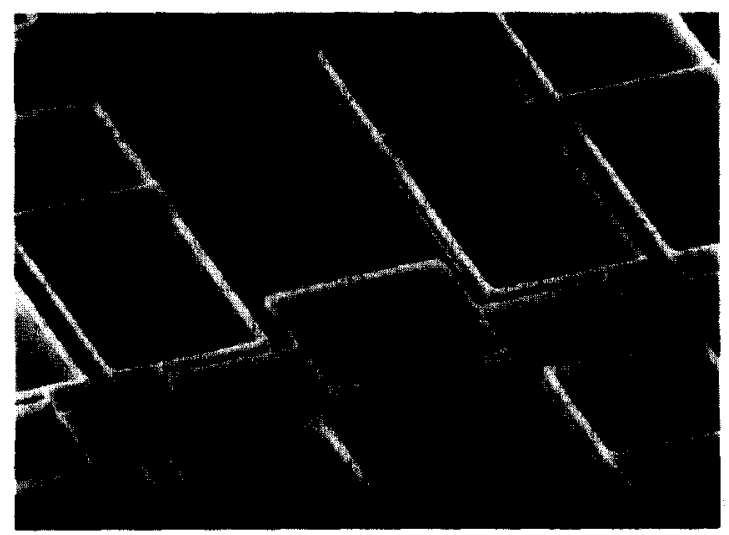

(a)

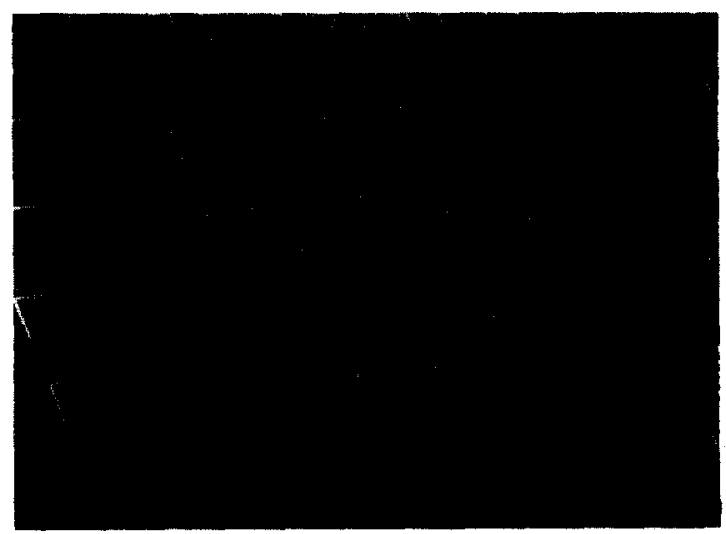

(b)

Fig. 8. Two-dimensional polysilicon mirror array: (a) close view of two mirrors (SEM); (b) corner of a $32 \times 32$ mirror array.

observed for the aluminum mirrors (Fig. 7(b)); it is probably due to the increased surface roughness caused by the $\mathrm{BHF}-\mathrm{K}_{2} \mathrm{Cr}_{2} \mathrm{O}_{7}$ etch solution. The measured forward surface reflectivities are given in Table 1 . While the values for silicon (38.1\%) and polysilicon (31.4\%) are normal for IC processing, the reflectivity of the aluminum mirror is rather low (66.5\%). A significant drop in reflectivity is caused by the etching in BHF- $\mathrm{K}_{2} \mathrm{Cr}_{2} \mathrm{O}_{7}$; before this final step, the aluminum reflectivity was $83.0 \%$.

\section{Mirror array}

Based on the encouraging results of the single torsional mirrors, two-dimensional arrays have been constructed. The polysilicon technology allows a simple fabrication of a two layer interconnection [23]; therefore, it has been chosen for the fabrication of a prototype array. The address electrode, which passes below the mirrors, is fabricated in a $0.2 \mu \mathrm{m}$ thick first polysilicon layer. The mirrors and their supports, which also serve as second electrode, are fabricated in a $2 \mu \mathrm{m}$ thick second polysilicon. In this way, a two-dimensional rectangular grid of electrodes is formed which allows, by properly choosing the voltages, to address every single mirror individually. A picture displaying details of two mirrors is given in Fig. 8(a). In Fig. 8(b), a comer of a $32 \times 32$ mirror array is shown.

\section{Conclusions}

Torsional micromirrors have been successfully fabricated in single crystal silicon, polycrystalline silicon and aluminum using the same set of masks. The characterization points out that working light modulators can be realized in each material. However, silicon and polysilicon devices present higher yield strains but also higher processing temperatures and switching voltages. On the other hand, aluminum mirrors have higher surface reflectivities. In polysilicon technology, a twodimensional array of micromirrors has been constructed for further evaluation.

\section{Acknowledgements}

We acknowledge Professor Dr Ph. Renaud of the CSEM and the Swiss Federal Institute of Technology Lausanne for inspiring discussions. Further, we owe thanks to Dr I. Kjelberg of the CSEM for performing the scattering measurements and to Dr F. Sollberger of the CSEM for advice concerning the development of the aluminum surface micromachining process. Finally, we are grateful to P.-A. Clerc and S. Jeanneret of the IMT laboratory as well as to the technical staff of the CSEM laboratory for assistance in the device fabrication.

This work was supported by the Swiss Foundation for Microtechnology Research (FSRM 90/08).

\section{References}

1 R. Vuilleumier, A.-E. Perret, F. Porret and P. Weiss, Novel electromechanical microshutter display device, Proc. SID Eurodisplay '84, Paris, France, Sept. 1984, pp. 41-44.

2 L.J. Hornbeck, Deformable-mirror spatial light modulators, Proc. Soc. Photo-Opt. Instrum. Eng., 1150 (1989) 86-102.

3 K.E. Mattson, Surface micromachined scanning mirrors, $M i$ croelectron. Eng., 19 (1992) 199-204.

4 K.E. Petersen, Silicon torsional scanning mirror, IBM J. Res. Develop., 24 (1980) 631-637.

5 K. Gustafsson and B. Hök, A silicon light modulator, J. Phys. E, 21 (1988) 680-685. 
6 V.P. Jaecklin, C. Linder, N.F. de Rooij, J.-M. Moret and R. Vuilleumier, Optical microshutters and torsional micromirrors for light modulator arrays, Proc. IEEE Micro Electro Mech. System Workshop, Fort Lauderdale, FL, USA, Feb. 1993, pp. 124-127.

7 J. Brugger, R.A. Buser and N.F. de Rooij, Micromachined atomic force microprobe with integrated capacitive read-out, J. Micromech. Microeng., 2 (1992) 218-220.

8 R.A. Buser, N.F. de Rooij and L. Schultheis, Silicon pressure sensor based on a resonating element, Sensors and Actuators A, 25-27 (1991) 717-722.

9 C. Harendt, B. Höfllinger, H. Graf and E. Penteker, Silicon direct bonding for sensor applications: characterization of the bond quality, Sensors and Actuators A, 25-27 (1991) 87-92.

10 C. Linder, T. Tschan and N.F. de Rooij, Deep dry etching of silicon - a novel micromachining technique, Sensors Mater., 3 (1992) 311-324.

11 C. Linder and N.F. de Rooij, Investigations on free-standing polysilicon beams in view of their application as transducers, Sensors and Actuators, A21-A23 (1990) 1053-1059.

12 U.R. Evans, The Corrosion and Oxidation of Metals: Scientific Principles and Practical Applications, St. Martin's Press, New York, 1960, Ch. 5.

13 J.Y. Tsao and D.J. Ehrlich, Laser-controlled wet chemical etching for corrective trimming of thin films, J. Electrochem. Soc., 133 (1986) 2244-2248.
14 H. Guckel, T. Randazzo and D.W. Burns, A simple technique for the determination of mechanical strain in thin films with applications to polysilicon, J. Appl. Phys., 57 (1985) 1671-1675.

15 R.L. Alley, G.J. Cuan, R.T. Howe and K. Komvopoulos, The effect of release-etch processing on surface microstructure stiction, Tech. Digest, IEEE Solid-State Sensors and Actuators Workshop, Hilton Head Island, SC, USA, June 1992, pp. 202-207.

16 Y.C. Tai and R.S. Muller, Fracture strain of LPCVD polysilicon, Tech. Digest, IEEE Solid-State Sensor and Actuator '88, Hilton Head Island, SC, USA, June 6-9, 1988, pp. 88-91.

17 S. Timoshenko, Strength of Materials, R.E. Krieger, Malabar, FL, USA, 1958.

18 R.L. Eisner, Tensile tests on silicon whiskers, Acto Metall., 3 (1955) 414-415.

19 G.L. Pearson, W.T. Read, Jr and W.L. Feldmann, Deformation and fracture of small silicon crystals, Acta Metall., 5 (1955) 181-191.

20 S. Johansson, J.- $\AA$. Schweitz, L. Tenerz and J. Tirén, Fracture testing of silicon microelements in situ in a scanning electron microscope, J. Appl. Phys., 63 (1988) 4799-4803.

21 H.M. Trent, D.E. Stone and L.A. Beaubine, in D.E. Gray (ed.), American Institute of Physics Handbook, McGraw-Hill, New York, 1982, Ch. 2e, pp. 2-62.

22 A. de S. Jayatilaka, Fracture of Engineering Brittle Materials, Applied Science, London, 1979.

23 V.P. Jaecklin, C. Linder, N.F. de Kooij and J.-M. Moret, Comb actuators for xy-microstages, Sensors and Actuators $A$, 39 (1993) 83-89. 